\title{
Rancang Bangun Role-Playing Game Peristiwa Patriotik Merah Putih 14 Februari 1946 di Sulawesi Utara
}

\author{
Octavianus Elricth Waters Modami, Rizal Sengkey, Virginia Tulenan \\ Teknik Informatika Universitas Sam Ratulangi Manado \\ Jl. Kampus UNSRAT Bahu, 95115 \\ 110216122@student.unsrat.ac.id, rizalsengkey@gmail.com, virginia.tulenan@unsrat.ac.id
}

\begin{abstract}
Abstrak - Game merupakan salah satu aplikasi kategori hiburan yang populer di aplikasi mobile saat ini. Dengan menggunakan media game, secara tidak langsung pengguna mengetahui isi informasi yang diberikan oleh pembuat game. Banyak peristiwa sejarah yang tidak diperkenalkan pada saat pelajaran sekolah seperti peristiwa patriotik merah putih 14 februari 1946. Tujuan penelitian ini adalah mengembangkan sebuah game yang bertujuan mengenalkan sejarah peristiwa patriotik 14 februari 1946 di Sulawesi Utara, aplikasi game ini diberi nama "Hero Celebes". Game ini mempunyai genre role-playing dibangun menggunakan metode perancangan Player-Centric Game Design. Metode perancangan yang digunakan memiliki 3 tahap pembuatan yaitu: Tahap Konsep, Tahap Elaborasi, Dan Tahap Tuning. Pembuatan aplikasi game ini menggunakan UNITY3D 5.3 sebagai game engine dikarenakan aplikasi ini dapat digunakan tanpa harus membayar (gratis). Berdasarkan penelitian ini dapat diketahui bahwa media game bisa digunakan untuk menyampaikan informasi peristiwa sejarah kepada masyarakat.
\end{abstract}

Kata kunci: Game, Game Engine, Peristiwa Patriotik merah putih 14 Februari 1946 di Sulawesi Utara, Player-Centric Game Design, Role-Playing Game, UNITY3D.

Abstract - Game is currently one of the popular entertainment category applications in mobile applications. By using the media game, indirectly, users know the content of the information provided by the game maker. Many historical events are not introduced at the school such as the red and white patriotic events of 14 February 1946. The purpose of this study was to develop a game that aims to introduce the history of patriotic events of February 14, 1946 in North Sulawesi, a game application is named "Hero Celebes". This game has the genre of role-playing constructed using the method Player-Centric Game Design. The design method used has 3 stages of manufacture, namely: Phase Concepts, Elaboration Phase, and Phase Tuning. This gaming application development using Unity $3 D 5.3$ as game engine because this application can be used without having to pay (free). Based on this research can be seen that the gaming media can be used to convey information to the public historical events.

Keyword: Game, Game Engine, Player-Centric Game Design, Red and white patriotic events of 14 February 1946 in North Sulawesi Role-Playing Game, UNITY3D.

\section{PENDAHULUAN}

Pada masa sekarang, kemajuan teknologi informasi begitu pesat, sehingga setiap masyarakat terbiasa akan bermacam-macam aplikasi perangkat lunak yang digunakan sesuai kebutuhan masyarakat. Menurut riset yang dilakukan oleh Perusahaan Raksasa Google dan TNS Australia pada tahun 2015, aplikasi mobile dengan kategori entertainment (hiburan) merupakan salah satu kategori yang paling populer di Indonesia sehingga terdapat peluang untuk diminati oleh para pengguna di Indonesia

Aplikasi Game merupakan salah satu aplikasi hiburan yang diminati oleh para pengguna aplikasi mobile. Para pengguna aplikasi game secara tidak sadar mendapatkan informasi konten yang dibuat oleh para pengembang game. Menurut Ernest Adam [2007], Game muncul dari keinginan manusia untuk bermain dalam kapasitas yang tidak nyata/virtual. Fenomena psikologi saat memainkan aplikasi game memiliki manfaat antara lain memecahkan mister, memanajemen elemen-elemen game dan menghafal semua konten informasi. Pada sebuah Game dengan genre Role-Playing Game (RPG) mengutamakan sebuah cerita dimana pemain akan mengenal tentang tokoh dan latar dari sebuah dunia game. Pada genre ini dikenalkan karakteristik dari alur cerita yang akan diinformasikan dalam permainan sehingga bisa membuat player berkeinginan menambah informasi tentang karakter tersebut. Contoh role-playing game yang bercerita tentang tokoh adalah Arjuna Adventure dan Kuru Setra The Mighty Wars. Kedua Game ini sama-sama bergenre role-playing game yang dipadukan dengan genre yang lain. Pada aplikasi game Arjuna Adventure menceritakan petualangan seorang tokoh bernama arjuna berjuang untuk membebaskan seorang putri sedangkan pada aplikasi game Kuru Setra The Mighty Wars menceritakan tentang perang bharatayuda yang terjadi pada kisah Mahabarata. 
Negara Indonesia memiliki cerita sejarah perjuangan kemerdekaan yang menarik. Negara kita ini faktanya merupakan bekas jajahan oleh negara lain seperti Portugis, Jepang dan Belanda. Karena usaha dari para pejuang kemerdekaan generasi penerus sekarang dapat menikmati kemerdekaan. Oleh karena itu pentingnya generasi penerus bangsa sekarang mengetahui tentang peristiwa-peristiwa perlawanan seperti perlawanan di Bandung pada 23 Maret 1946 dan perlawanan di Surabaya 10 November 1945. Peristiwa patriotik merah putih 14 Februari di Sulawesi Utara juga merupakan peristiwa yang sama pentingnya dengan peristiwa perlawanan di daerah lain. Sejarah peristiwa ini merupakan bukti sumbangsih perjuangan para pejuang di Sulawesi Utara pada kemerdekaan Indonesia. Namun perkembangan jaman sejarah peristiwa ini kurang dikenal oleh sebagian masyarakat dibandingkan dengan peristiwa perlawanan di Bandung maupun di Surabaya.

Berdasarkan latar belakang yang telah diuraikan, Penulis berkeinginan membuat suatu game yang menceritakan peristiwa patriotik merah putih 14 februari 1946 di Sulawesi Utara. Pada game ini pemain akan berperan sebagai seorang tokoh yang berperang melawan tentara-tentara dan pemimpin penjajah untuk merebut kemerdekaan Indonesia di Sulawesi Utara. Pengguna diharapkan bisa merasakan sensasi perang yang terjadi dan menjadi pemacu untuk pengembangan game yang lainnya untuk memanfaatkan ide-ide lokal dalam membangun game.

\section{A. Game}

Game dapat didefinisikan sebagai aktivitas bermain dalam konteks virtual dimana para pesertanya mencoba mencapai tujuan yang diberikan dengan aturan yang ditetapkan pada sebuah game (Ernest Adam, 2010) [1].

\section{B. Peristiwa Patriotik Merah Putih 14 Februari 1946 di Sulawesi Utara}

Peristiwa Patriotik Merah Putih 14 Februari 1946 di Sulawesi Utara merupakan bukti dari perjuangan masyarakat Sulawesi Utara turut mengambil bagian dalam kemerdekaan Negara Republik Kesatuan Indonesia (NKRI) dimana setelah kejadian ini wilayah NKRI meliputi seluruh pulau Sulawesi. Pada Peristiwa ini dipimpin oleh pahlawan nasional B.W. Lapian bersama Ch. Taulu (Ben Wowor, 1985)[2].

\section{Game Engine}

Di awal tahun 2000-an, terdapat banyak game engine seperti 3dmax dan blender yang dilengkapi oleh world editor. Game engine merupakan sepaket software dengan berbagai macam fitur membantu dalam proses pembuatan game. Sebuah Developer Team memerlukan sebuah game engine yang mendukung saat pengembangan game yang diinginkan. Biasanya dalam game engine mempunyai fitur-fitur seperti world editor, code editor, function rendering, dan assets. World Editor digunakan untuk membangun game world. Code Editor berfungsi untuk menambahkan source code pada objek dalam game. Funciton Rendering digunakan untuk menggerakan, memberikan audio, dan elemen-elemen tambahan pada sebuah game.Yang terakhir adalah pengaturan assets penyusun sebuah game (Roedavan, 2014)[3].

\section{Unity3D}

Unity Technologies dibangun tahun 2004 oleh David Helgason, Nicholas Francis dan Joachim Ante. Game engine ini dibangun atas dasar kepedulian mereka terhadap indie developer yang tidak bisa membeli game engine karena terlalu mahal. Keunggulan unity adalah kita dapat mendapatkannya dengan gratis dan memungkinkan seorang individu dan kelompok membuat sebuah game dengan mudah dan cepat selain itu unity juga sebuah engine multiplatform yang memungkinkan game yang dibangun di publish untuk berbagai platform, seperti windows, android, mac , ios, ps3 dan juga wii. Keunggulan dari sebuah Game Engine UNITY:

- Multifungsi dalam membangun game berdimensi dua dan berdimensi tiga (2D dan 3D)

- Game yang dibuat dapat Implementasikan di beberapa macam platform

- Game Engine dapat digunakan gratis dan juga berbayar.

\section{E. Player-Centric Game Design}

Menurut Ernest Adam, Player-centric game design adalah sebuah perancangan yang membayangkan penglihatan dari sisi pemain yang akan menggunakan game tersebut. Untuk membuat sebuah game menarik, sebuah pengembang harus membayangkan bagaimana dia akan menjadi sebuah pemain dan membuat pemain untuk lebih tertarik. Dalam metode perancangan ini terdapat 3 bagian besar yaitu tahap konsep, tahap elaborasi, dan tahap tuning. Pada masing-masing tahap hanya tahap elaborasi terjadi pengulangan perancangan untuk menyempurnakan fitur-fitur yang disesuaikan pada elaborasi sebelumnya. Berikut rincian dari 3 tahapan perancangan player-centric game design:

1) Concept Stage adalah tahapan pertama yang berisi tentang fitur-fitur apa yang akan di tawarkan game yang dibangun untuk pengguna. Pada tahapan ini akan menggambarkan peranan pengguna dan target dari pengguna game ini nantinya.

2) Elaboration Stage adalah tahapan dimana kita bisa menambahkan sebagian besar perancangan dan menentukan keputusan dalam sebuah prototipe dan playtesting.

3) Tuning Stage adalah tahapan dimana kita tidak akan menambahkan fitur baru hanya akan memoles bagian kecil komponen game 


\section{METODOLOGI PERANCANGAN}

\section{A. Kerangka Kerja}

Dalam melakukan perancangan dan pembuatan game, dibutuhkan kerangka kerja agar pembuatan game dapat berjalan dengan baik. Berikut ini merupakan kerangka kerja yang digunakan berdasarakan metode perancangan player-centric game design

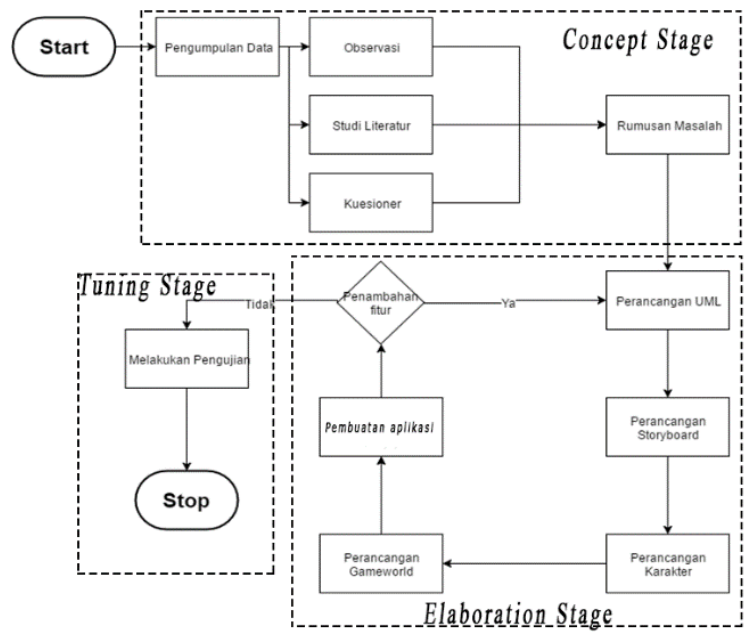

Gambar 1. Kerangka Kerja

\section{B. Tahap Konsep}

Pada tahap konsep dilakukan pengumpulan data dengan 3 macam cara yaitu observasi, studi literatur, dan kuesioner untuk menyusun konsep awal game yang akan dibangun oleh penulis. Hasil dari tahap konsep adalah spesifikasi dasar game yang sudah ditentukan sesuai dengan pengumpulan data. Berikut rincian dan tujuan masing-masing cara pengumpulan data:

1) Observasi

Observasi merupakan cara pengumpulan data untuk pembuatan konsep dengan membandingkan aplikasi game sejenis yang sudah pernah dibuat oleh pengembang lainnya. Pada observasi penulis membandingkan aplikasi game Final Fantasy Tactic dari pengembang SquareEnix dibandingkan dengan Reaper: Tale of a pale Swordsman dikembangkan oleh Hexage. Hasil perbandingan dapat dilihat pada tabel 1 .

\section{2) Studi Literatur}

Pada studi literature dilakukan untuk pengumpulanpengumpulan data-data pada media online, buku-buku, serta tutorial yang mendukung pembuatan dan perancangan game.

\section{3) Kuesioner}

Pada tahapan kuesioner, penulis melakukan pencarian informasi tentang kebutuhan sistem game pada pengguna, platform yang akan diterapkan pada game serta pengetahuan masyarakat terhadap objek informasi sejarah peristiwa patriotik merah putih 14 Februari 1946 di Sulawesi Utara. Pada tahap ini sangat penting karena menentukan platform game yang akan dibangun pada kuesioner diketahui bahwa kebanyakan pengguna mobile menggunakan sistem operasi Android.
Sehingga platform game akan di terapkan pada sistem operasi Android lihat gambar 2.

\section{Tahap Elaborasi}

Tahap elaborasi merupakan tahap kedua dari perancangan game. Pada tahap ini penulis merancang dan membuat prototip game berdasarkan hasil rancangan yang telah dibuat pada sebelumnya pada perancangan UML(Unified Modeling Language) untuk mendeskripsikan peranan dari pengguna aplikasi game yang akan dibuat, perancangan storyboard untuk target tampilan-tampilannya, perancangan karakter-karakter, perancangan gameworld / lingkungan pada area, serta pengujian pada kesalahan-kesalahan pada pembuatan. Berikut hasil perancangan dari beberapa tahap elaboras yang dilakukan:

1) Perancangan UML

Pada Perancangan UML seperti yang disebutkan diatas mendeskripsikan peranan pengguna pada aplikasi game. Pengguna aplikasi game biasanya disebut player / pemain. Pada perancangan ini menggunakan diagram use-case untuk mendeskripsikan aksi-aksi yang dapat dilakukan player. Terdapat 5 aksi utama player yang terdapat pada game ini lihat gambar 3 .

2) Perancangan Storyboard

Perancangan ini dilakukan untuk menentukan elemen-elemen tampilan yang akan dipresentasikan pada pemain. Perancangan ini berfungsi sebagai acuan tampilan yang membantu penulis untuk membuat sebuah game. Pada perancangan ini akan berisikan rincianrincian tampilan seperti font tulisan, tujuan tampilan, serta suara yang digunakan terdapat 7 tampilan utama dan urutannya lihat gambar 4.

3) Perancangan Karakter

Sebelum pembuatan karakter perlu dibuat konsep awal karakter dan deskripsi agar konten tetap konsisten terhadap tema yang dibawa oleh game tersebut. Pada game ini terdapat 1 karakter utama, 2 karakter musuh, dan 2 karakter bos musuh lihat gambar 5. Karena bertemakan sejarah yang mengutamakan keaslian cerita maka pakaian karakter utama disesuaikan dengan seragam tentara belanda pada perang dunia ke 2 .

\section{4) Perancangan Game World}

Pada proses ini akan menentukan daerah gameplay/ daerah bermain dari karakter yang mendukung pemain dalam berimajinasi tentang kejadian peristiwa merah putih 14 februari 1946 di Sulawesi Utara. Pada ceritanya terbagi dalam 2 tempat yaitu markas senjata di teling dan wilayah jalan ke kota manado

\section{Tahap Tuning}

Pada tahap ini game yang dibuat dapat dimainkan, sehingga diperlukan proses tuning peningkatan kualitas dengan melakukan pengujian pada pengguna dan perangkat keras yang berbeda untuk mengetahui kualitas dari sebuah game. Pada tahap ini penulis melakukan ujicoba pada 3 perangkat mobile yang berbeda dan melakukan uji permainan pada beberapa pengguna. 


\begin{tabular}{|c|c|c|}
\hline $\begin{array}{l}\text { Elemen } \\
\text { /Game }\end{array}$ & $\begin{array}{l}\text { Reaper: Tale } \\
\text { of a pale } \\
\text { Swordsman }\end{array}$ & $\begin{array}{c}\text { Final Fantasy } \\
\text { Tactics }\end{array}$ \\
\hline Platform & Android, IOS & $\begin{array}{c}\text { Playstation, } P s P \\
\text { Android, IOS }\end{array}$ \\
\hline Genre & $\begin{array}{c}\text { Action Role } \\
\text { Playing Game }\end{array}$ & $\begin{array}{l}\text { Strategy Role } \\
\text { Playing Game }\end{array}$ \\
\hline $\begin{array}{l}\text { Jumlah } \\
\text { Karakter }\end{array}$ & $\begin{array}{c}\text { Single } \\
\text { Character }\end{array}$ & Multi Character \\
\hline Alur Cerita & Linear & Linear \\
\hline $\begin{array}{c}\text { Sudut } \\
\text { Pandang yang } \\
\text { digunakan }\end{array}$ & Orang ketiga & Orang Ketiga \\
\hline Navigasi & $\begin{array}{l}\text { Maju, mundur, } \\
\text { atas, bawah }\end{array}$ & $\begin{array}{c}\text { Kanan, kiri, } \\
\text { depan, belakang }\end{array}$ \\
\hline Grafik & $2 \mathrm{D}$ & $2 \mathrm{D}$ \\
\hline Fitur sistem & $\begin{array}{l}\text { Leveling, } \\
\text { special skill, } \\
\text { side quest }\end{array}$ & $\begin{array}{l}\text { Leveling, job } \\
\text { class, side quest, } \\
\text { special skill }\end{array}$ \\
\hline Battle System & Real Time & Turn Base \\
\hline Rating & - & ESRB : Teen \\
\hline
\end{tabular}

Tabel 1 Hasil Observasi pada Aplikasi game sejenis

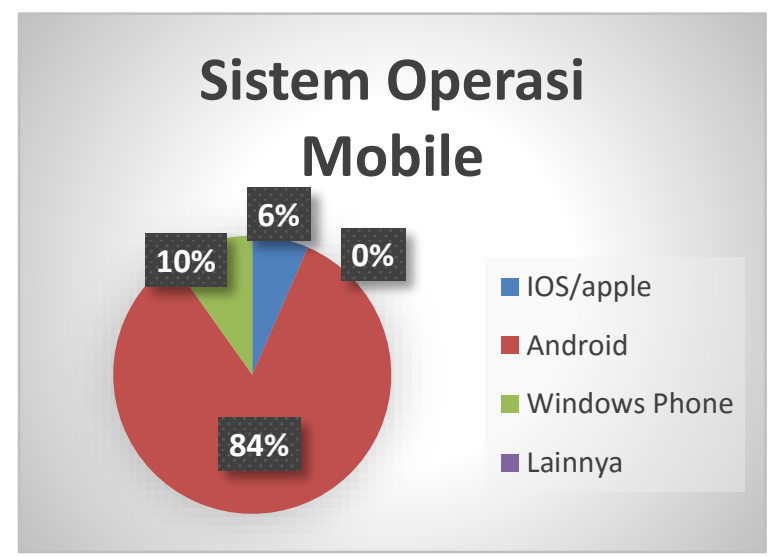

Gambar 2 Hasil Kuesioner Platform game

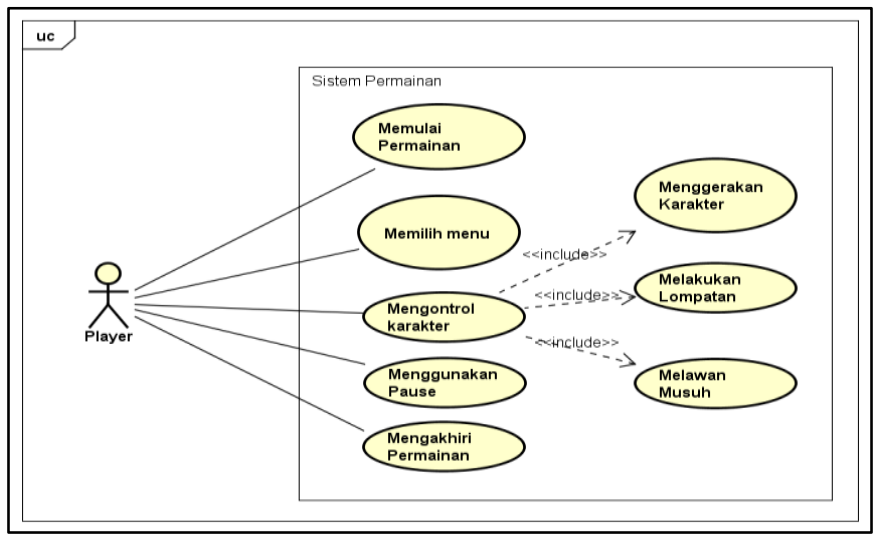

Gambar 3. Use Case Diagram Pemain

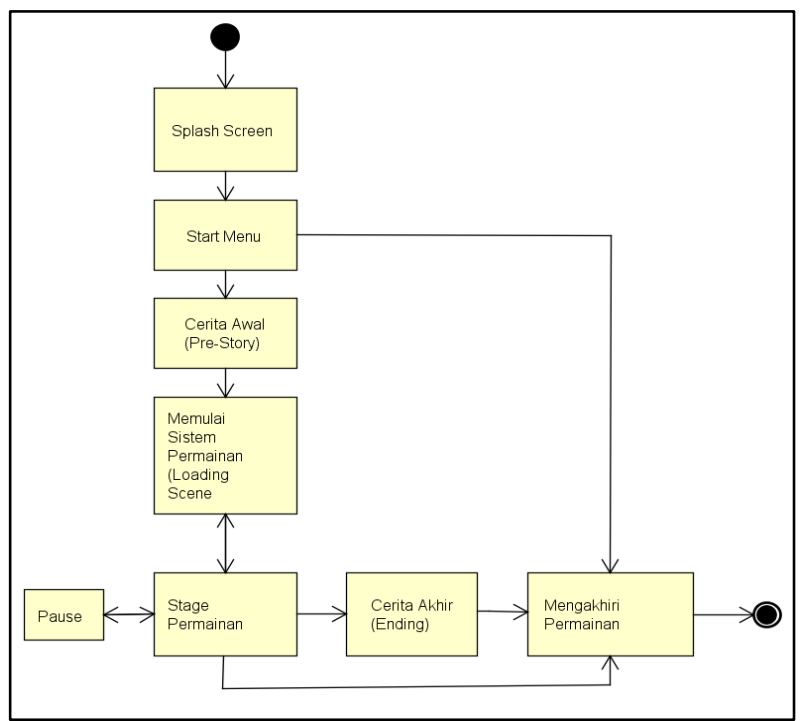

Gambar 4. Diagram alir tampilan-tampilan pada game

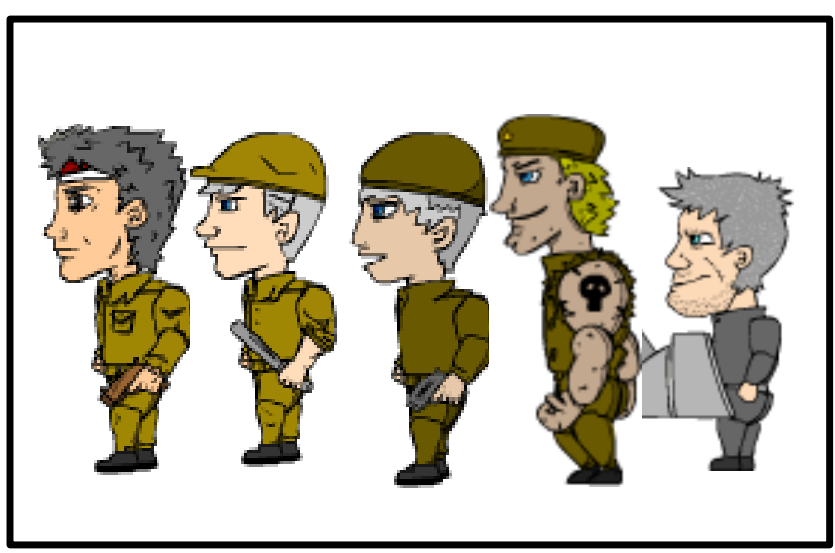

Gambar 5. Karakter-karakter pada game 


\section{HASIL DAN PEMBAHASAN}

\section{A. Mekanisme Alur Scene Pada Game}

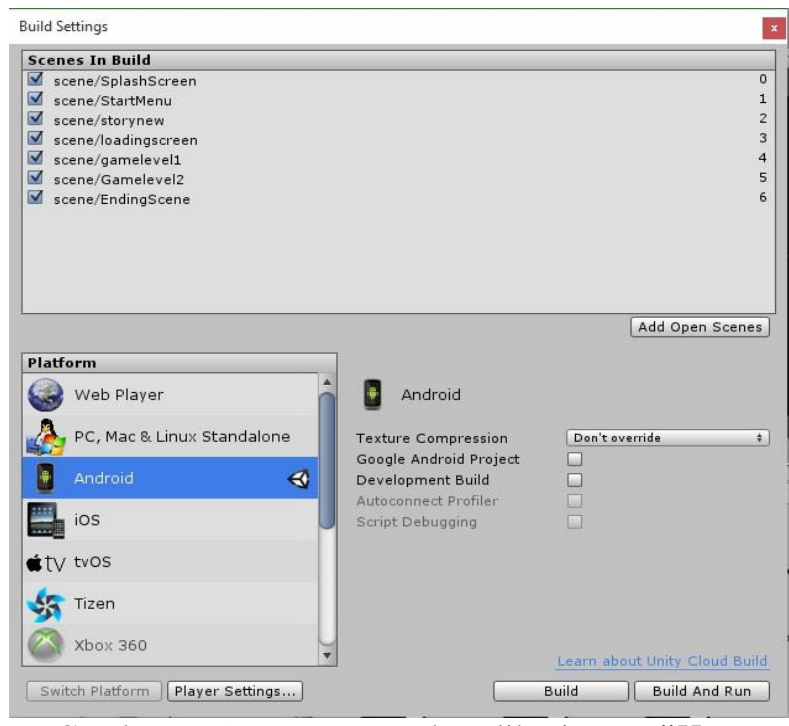

Gambar 6. Scene-scene pada aplikasi game”Hero Celebes”

Pada gambar 6 merupakan scene-scene game yang sudah dibuat sesuai dengan susunan diagram alir pada mekanisme game. Pada alur pertama pemain dibawa kedalam scene splash yang akan menampilkan logo universitas samratulangi sebagai identitas institusi pembuat game berasal lihat gambar 7. Selanjutnya pemain akan dibawa kedalam scene menu utama yang menampilkan 4 tombol perintah yaitu tombol how to play untuk menampilkan menu yang berisi tentang bagaimana cara bermain, tombol about berisikan deskripsi singkat tentang tema permainan dan informasi sejarah peristiwa 14 februari 1946, tombol exit untuk mengakhiri permainan, dan tombol start digunakan untuk memulai permainan lihat gambar 8. Pada saat pemain menekan tombol start pemain diarahkan ke scene awal cerita lihat gambar 9. Pada scene ini pemain akan melihat sebuah teks-teks yang menceritakan latar belakang terjadinya peristiwa patriotic 14 februari 1946 di Sulawesi Utara pada masa akhir perang dunia ke 2. Scene awal cerita memiliki durasi sekitar 3 menit untuk menuju scene berikutnya tetapi pada scene cerita disisipkan tombol skip yang tidak terlihat untuk melewatkan scene ini. Setelah scene awal cerita, pemain diarahkan pada scene loading yang bertugas sebagai perantara antar stage dari permainan utama lihat gambar. Pada scene permainan terbagi menjadi 2 stage. Stage pertama merupakan awal dimana pemain mengenal karakter pejuang yang memulai kejadian dengan mensabotase dan membebaskan para tawanan di markas senjata sekutu teling. Pada stage ini pemain diberikan misi untuk mengalahkan seorang perwira bernama kapten bloom dan membebaskan para penduduk dari penjara lihat gambar 10. Setelah pemain berhasil menjalankan misi, pemain dapat melanjutkan pada stage kedua. Pada stage kedua merupakan akhir pertempuran antara tentara pergerakan Sulawesi utara melawan sekutu sehingga pemain diberikan misi untuk mengalahkan pimpinan utama sekutu letnan kolonel De
Vries yang berada disekitar wilayah kota Manado lihat gambar 11. Setelah pemain selesaikan stage kedua maka pemain diarahkan pada scene ending. Pada scene ending menceritakan akhir dari kejadian peristiwa patriotic merah putih 14 Februari 1946 yang diakhiri dengan upacara bendera merah putih di balai kota manado lihat gambar 12. Setelah teks cerita berakhir ditampilkan teksteks yang berisi tentang ucapan terima kasih penulis untuk kontribusi orang-orang yang membantu dalam pembuatan. Berikutnya pemain diarahkan kembali ke scene menu utama agar pemain dapat memilih memainkan ulang atau mengakhiri permainan.

\section{B. Karakter}

.Berdasarkan perancangan fungsional, pemain dapat memberikan instruksi seperti menggerakan, melakukan lompatan, dan menyerang. Maka terdapat 3 tombol yang memberikan perintah pada karakter untuk melakukan instruksi tersebut. Pada script player yang dibuat 2 fungsi yang digunakan untuk mengatur semua masukan pada tombol terdiri dari handle movement dan handle input. Fungsi pertama digunakan untuk mengontrol pergerakan karakter dan fungsi kedua digunakan untuk melakukan aksi-aksi karakter.

Berdasarkan perancangan karakter dibuat rangkaian animasi yang dimainkan dalam kondisi tertentu dalam permainan. Pada karakter yang dibangun animasi yang digunakan dibagi menjadi 2 layer terdiri dari layer pertama diberi nama ground yaitu kondisi dimana karakter berada pada pijakan dan layer air yaitu kondisi dimana karakter tidak menyentuh pijakan dan terpengaruh gravitasi. Pada gambar 13 dapat dilihat beberapa animasi yang digunakan, Dimulai dari idlePlayer digunakan saat pemain diam. Disebelah kiri kita dapat melihat parameter-parameter yang digunakan untuk membuat kondisi-kondisi kapan animasi akan diputar. Pada Gambar 14 animator ini akan dijalankan saat pemain tidak menyentuh pijakan dalam game. Pada layer ini dipengaruhi gaya gravitasi pada scene permainan. Pada setiap blok dimasukan beberapa animasi yang telah dibuat. Pada karakter utama terdapat 8 animasi yang akan digunakan pada animator layer air dan ground. Pengaturan pada aksi-aksi karakter terdiri dari 3 core mechanic yaitu: karakter berjalan, karakter melompat, dan karakter melakukan serangan.

\section{Pengujian pada perangkat mobile yang berbeda}

Pada pengujian game dilakukan pada 3 perangkat mobile yang berbeda yaitu pada Asus Zenfone 2, Xiaomi mi4, dan Samsung Galaxy Note II N7100 memiliki spesifikasi yang berbeda-beda. Pada gambar 15 menunjukan bahwa aplikasi game dapat dijalankan pada 3 perangkat keras yang berbeda yang mempunyai sistem operasi Android minimal versi 4.0. Perbedaan tampilan dapat dilihat pada tabel 2 menunjukan bahwa tampilan pada aplikasi game fleksibel dapat mengikuti resolusi berbeda-beda pada masing-masing perangkat keras. 


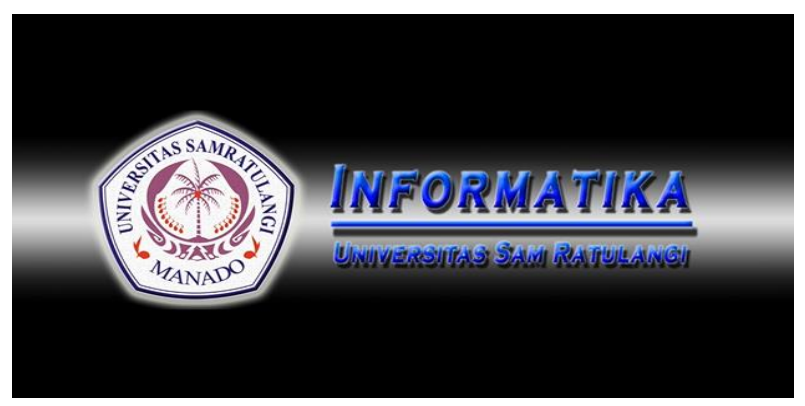

Gambar 7 Tampilan Scene Splash

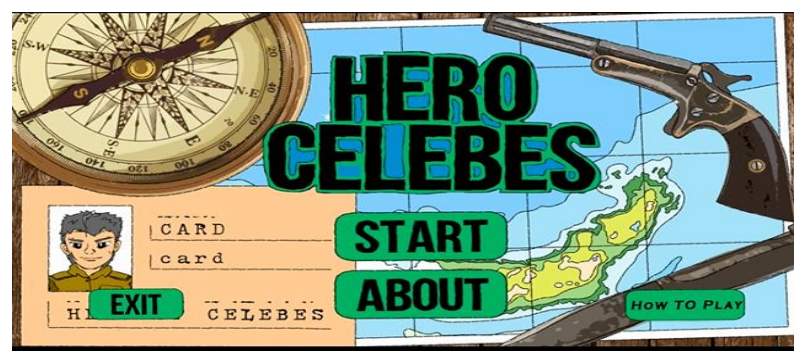

Gambar 8 Tampilan Scene Menu Utama

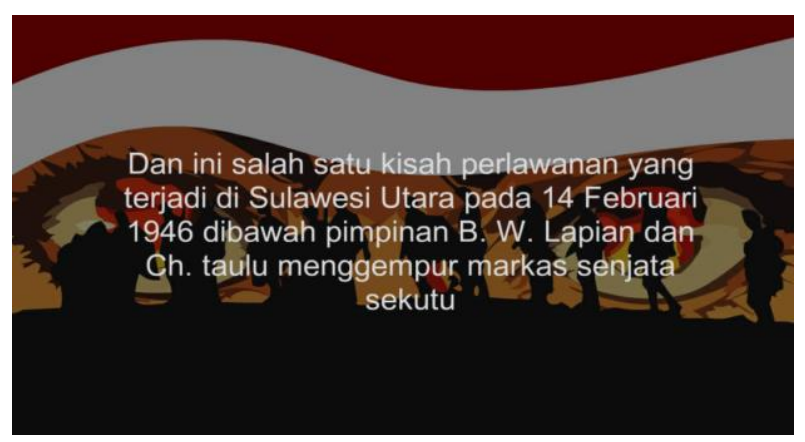

Gambar 9 Tampilan Scene Awal Cerita

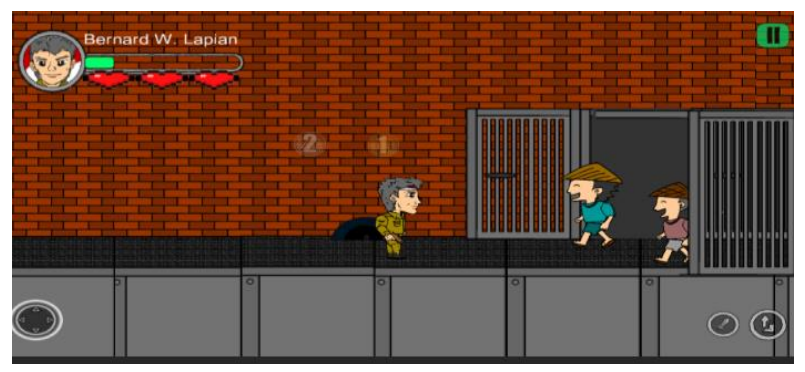

Gambar 10 Tampilan Scene permainan stage 1

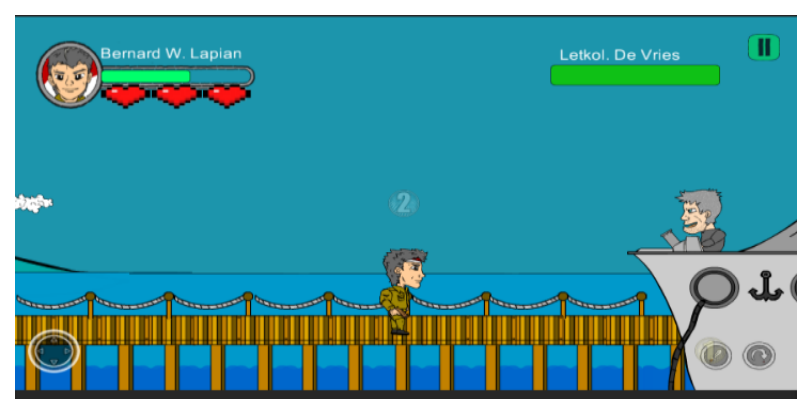

Gambar 11 Tampilan Scene permainan stage 2

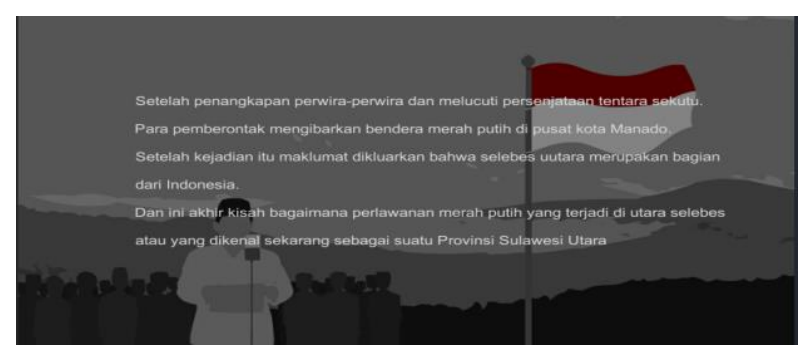

Gambar 12 Tampilan Scene Ending

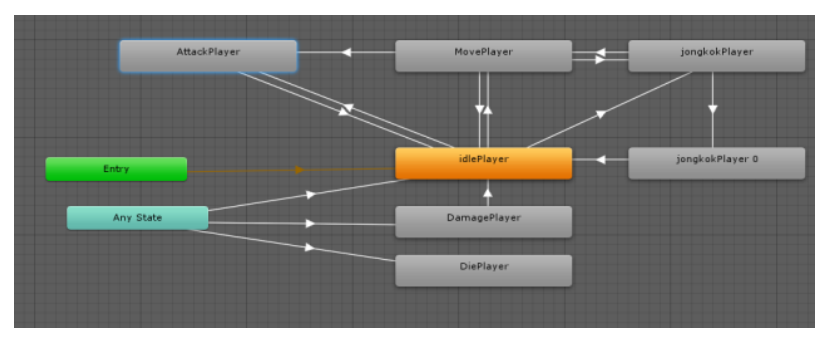

Gambar 13 Animator Karakter Ground Layer

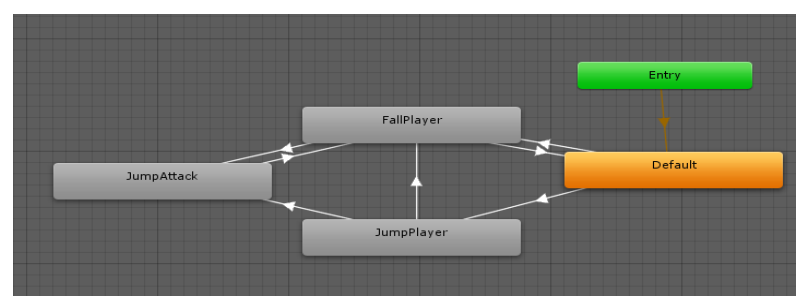

Gambar 14 Animator Karakter Air Layer

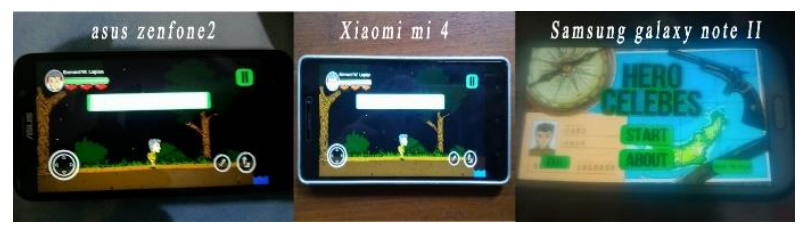

Gambar 15 Hasil Ujicoba Aplikasi Game "Hero Celebes" Pada Perangkat Mobile yang Berbeda

\begin{tabular}{|l|l|l|l|}
\hline $\begin{array}{l}\text { Elemen- } \\
\text { elemen } \\
\text { game }\end{array}$ & $\begin{array}{l}\text { Asus } \\
\text { Zenfone 2 }\end{array}$ & $\begin{array}{l}\text { Xiaomi } \\
\text { mi4 }\end{array}$ & $\begin{array}{l}\text { Samsung } \\
\text { Galaxy Note } \\
\text { II N7100 }\end{array}$ \\
\hline Teks & $\begin{array}{l}\text { Lebih } \\
\text { besar }\end{array}$ & $\begin{array}{l}\text { Sama } \\
\text { seperti } \\
\text { Samsung }\end{array}$ & $\begin{array}{l}\text { Sama seperti } \\
\text { Xiaomi }\end{array}$ \\
\hline Gambar & $\begin{array}{l}\text { Lebih } \\
\text { besar }\end{array}$ & $\begin{array}{l}\text { Sama } \\
\text { seperti } \\
\text { Samsung }\end{array}$ & $\begin{array}{l}\text { Sama } \\
\text { seperti } \\
\text { Xiaomi }\end{array}$ \\
\hline Suara & $\begin{array}{l}\text { Berjalan } \\
\text { dengan } \\
\text { baik }\end{array}$ & $\begin{array}{l}\text { Berjalan } \\
\text { dengan } \\
\text { baik }\end{array}$ & $\begin{array}{l}\text { Berjalan } \\
\text { dengan baik }\end{array}$ \\
\hline
\end{tabular}

Tabel 2 Perbandingan elemen-elemen game pada perangkat mobile yang berbeda 


\section{Kuesioner Evaluasi Aplikasi Game pada Pengguna}

Setelah pengujian perangkat keras maka dilakukan pengujian materi tentang konten atau kualitas aplikasi game "Hero Celebes" pada pengguna dan mengambil saran serta masukan untuk pengembangan aplikasi game selanjutnya. Uji coba bermain dan pengambilan kuesioner diadakan pada bulan September 2016 dengan total responden 20 orang. Pengambilan sampel responden dilakukan secara acak.

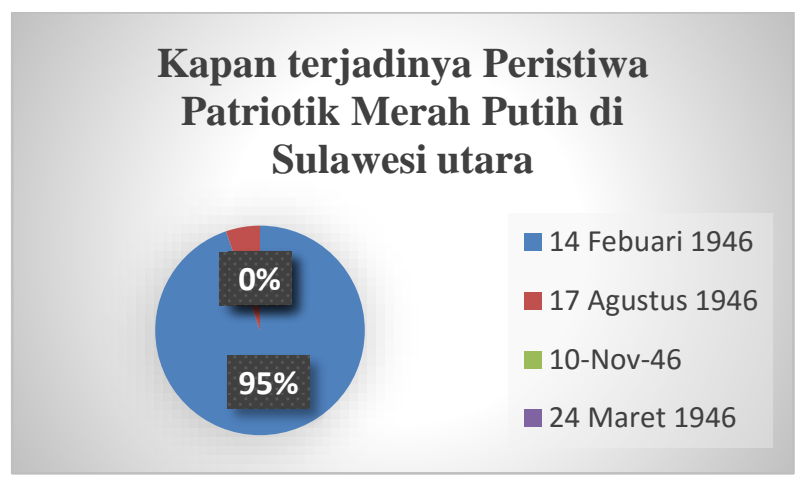

Gambar 16 Hasil Kuesioner tentang tanggal peristiwa sejarah dalam game.

Pada hasil kuesioner dapat dilihat bahwa responden dengan memainkan game ini mengetahui tanggal kejadian peristiwa patriotik 14 Februari 1946 di Sulawesi Utara dengan benar lihat gambar 16.

\section{PENUTUP}

\section{A. Kesimpulan}

Berdasarkan dari pembahasan-pembahasan pada bab-bab sebelumnya, maka dapat ditarik kesimpulan dari Skripsi "Rancang Bangun Role Playing Peristiwa Patriotik Merah-Putih 14 Februari 1946 di Sulawesi Utara", yaitu:

1) Game "Hero Celebes" dapat diselesaikan dengan metode perancangan player-centric game design

2) Hasil akhir dari penelitian ini adalah sebuah game animasi 2 dimensi bercerita tentang peristiwa patriotik merah putih pada tanggal 14 Februari 1946 di Sulawesi Utara

3) Prototype role-playing game "Hero Celebes" yang dibangun dapat memperkenalkan peristiwa patriotik merah putih 14 Februari 1946 di Sulawesi Utara kepada para pengguna.

\section{B. Saran}

Saran yang ingin disampaikan untuk Penulis untuk pengembangan game lebih lanjut adalah sebagai berikut:

1. Untuk Menambahkan tingkat kesulitan dari pemain dengan menambahkan atribut-atribut status point pada karakter musuh

2. Mengembangkan fitur-fitur yang lebih atraktif agar bisa lebih menarik seperti menggunakan pencarian
$\mathrm{A}^{*}$ untuk projectile musuh sehingga peluru dapat mengejar pemain dengan durasi waktu tertentu

3. Menggunakan Spesial Effect seperti ledakanledakan, atau bom yang bisa digunakan player.

\section{DAFTAR REFERENSI}

[1] Adam, Ernest. Fundamental of Game Design, Second Edition. Berkeley. United States of America.2010

[2] Ben Wowor. Sulawesi Utara Bergejolak: Peristiwa Patriotik Merah-Putih 14 Februari 1946. PD Karya Bani. Jakarta. 1985

[3] Roedavan Rickman. UNITY Tutorial Game Engine/ Informatika. Bandung. 2014

\section{SEKILAS TENTANG PENULIS}

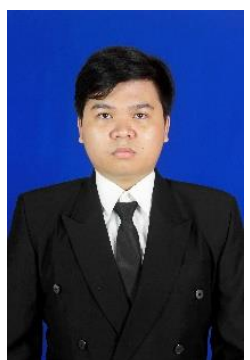

Octavianus Elricth Waters Modami, lahir di Denpasar, Bali pada tanggal 18 Oktober 1993. Anak ke-2 dari 2 bersaudara dengan pendidikan Sekolah Dasar Kristen Harapan Denpasar. Penulis lalu melanjutkan ke Sekolah Menengah Pertama Kristen 1 Harapan Denpasar. Lalu ke Sekolah Menengah Atas Negeri 1 Manado. Penulis kemudian melanjutkan studi di Fakultas Teknik, Jurusan Elektro, Program Studi Informatika, Universitas Sam Ratulangi Manado. Pada Tahun 2015 bulan Februari, penulis membuat Skripsi demi memenuhi syarat Sarjana (S1) dengan penelitian berjudul Rancang Bangun RolePlaying Game Peristiwa Patriotik 14 Februari 1946 di Sulawesi Utara yang dibimbing oleh dua dosen pembimbing yaitu Rizal Sengkey, ST., MT dan Virginia Tulenan, S.Kom., MTI Penulis dinyatakan lulus dari Program Studi Teknik Informatika Jurusan Elektro Universitas Sam Ratulangi Manado pada tanggal 2 Februari 2017. 